\title{
Programação direta da TV: sentido e hábito
}

Yvana FECHINE

Universidade Católica de Pemambuco/UNICAP 


\section{Resumo}

Este artigo se propõe a descrever um sentido que se instaura a partir da fruição da programação direta da TV, do contato com o fluxo televisual. Por ser direta e, por isso mesmo, estar conectada com uma temporalidade do cotidiano, a programação da TV faz sentido, antes de mais nada, como hábito. Com base nas formulações de Eric Landowski para o desenvolvimento de uma semiótica das experiências, assume-se aqui como pressuposto que o hábito produz uma forma de estesia: um sentido que se dá como um tomar gosto na e pela própria repetição de um fazer, o que nos permite pensar num tipo de fruição que ressemantiza o ato mesmo de ver $T V$ diariamente.

\section{Palavras-chave}

fluxo, televisão, hábito, sentido

\section{Abstract}

This article intends to describe a sense that is established starting from the fruition of the direct programming of the TV, of the contact with the flow. For being direct and, for that reason, to be connected with a duration of the daily life, the programming of the TV makes sense, before anything else, as habit. Based on Eric Landowski's formulations for the development of a semiotics of the experiences, it is assumed here as presupposition that the habit produces an esthesis form: a sense that feels as a to take taste in the and for the own repetition of a to do, the one that allows think us in a fruition type that produces a new sense of the same act of to watch $T V$ daily.

\section{Key words}

flow, television, habit, sense 


\section{Televisão e hábito}

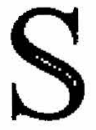

ão cada vez mais raros os indivíduos que, na sociedade contemporânea, vivem alijados da televisão. A programação da

TV pauta nossas conversas e nossos momentos de lazer, determina certas atividades domésticas e compromissos, tege nossos horários e embala inclusive nosso sono. Toda a produção da televisão é concebida para essa recepção inserida na vida cotidiana, no ambiente familiar e doméstico, em torno dos quais pode vir a se desenrolar uma intensa atividade social portadora de sentido por si só ou implicada diretamente nas interpretaçōes deflagradas diante do que se vê. Na televisão, as condições e as situações nas quais se acompanha a sua programação são parte intrínseca dos sentidos postos em circulação, não somente através dos programas exibidos, mas a partir da experiência mesma de ver $T V$, da exposição por si só ao fluxo televisual (Cf. Williams 1975). Para teóricos como John Fiske, a produção de sentido na TV depende, entre outros fatores, dos variados graus de atenção que um espectador socialmente situado (pertencente a uma classe social, gênero, etnia etc.) confere à própria TV (Cf. Fiske 1992). Preocupado em mostrar como as condições de recepção tomam parte, necessariamente, na produção de sentido na TV, John Ellis (1982) propõe a descrição desses modos de ver TV a partir de dois regimes de visão ou regimes de fruição: o regime do olhar (do olhar fixo, do fitar, do contemplar) e o regime da olhadela (do olhar furtivamente, da espiadela).

Estes regimes de visão podem ser considerados, em pólos opostos, como estados-limite dentro de uma pluralidade de formas intermediárias de fruição da TV. No regime da olhadela, o espectador 
apenas acompanha a televisão, muitas vezes enquanto realiza outras atividades, dedicando-lhe uma atenção intermitente ou esporádica. Neste caso, a TV é tão somente uma atividade secundária, que sugere agora uma investigação da nossa própria relação com o fluxo contínuo da sua programação. No regime do olhar, ao contrário, o espectador é completamente absorvido pelo que vê na TV, conferindo uma grande atenção àquilo que está sendo transmitido. Agora, assistir à TV é uma atividade primária, que nos permite, a partir de uma pressuposta relação do espectador com programas específicos, analisar os efeitos de sentido por estes produzidos. O reconhecimento desses dois regimes de visão determina também duas abordạgens distintas da produção de sentido na televisão: pode-se, por um lado, estudar a TV a partir na análise dos seus programas, considerados como elementos isolados (recortados, portanto, dentro da programação) e pode-se, por outro lado, pensar a TV a partir da sua programação, considerando indistintamente o fluxo televisual que se produz pela articulação contínua dessas unidades autônomas, embora interdependentes entre si, em função do seu próprio arranjo na grade.

$\mathrm{Na}$ primeira abordagem, o analista adota necessariamente como pressuposto a configuração do regime do olhar. Diante da particularização do objeto, o que se busca então é descrever os efeitos de sentido produzidos pelos programas-enunciados, recorrendo, no campo da semiótica discursiva, por exemplo, à análise dos diferentes níveis do percurso gerativo de sentido (o discursivo, particularmente). Na segunda abordagem, identificada aqui ao regime da olhadela, o sentido que se instaura não depende mais da leitura de um determinado programa dentro da programação porque, nesse caso, já nem há mais uma atenção dirigida a qualquer elemento particular. $O$ que se busca agora é descrever um tipo de sentido produzido na/pela prática diária de ligar a TV, simplesmente se expondo ao fluxo televisual (ligar a TV para não ver nada, ou seja, para não assistir a nada em especial): um sentido aquém e além dos próprios programas porque depende, antes de mais nada, de um tipo de contato do espectador com seu arranjo numa grade de programação que já lhe é familiar. Tratase aqui de um sentido que se instaura como um tipo de vivência 
cotidiana do espectador com a televisão; um sentido que se identifica com a reiteração do próprio contato do sujeito com sua programação; enfim, um sentido que se instaura no e pelo próprio hábito de assistir à televisão em determinadas condições e circunstâncias.

Esse sentido que se instaura tão somente nesse estar com a TV pode ser melhor compreendido através da própria noção de hábito, nos termos em que este é descrito por Eric Landowski (1998). Ou seja, como um sentido associado à ressemantização das nossas próprias práticas cotidianas. Assim como ler o jomal ao acordar, tomar café depois do almoço, fumar um cigatro após o jantar, ver $T V$ adquire aqui o mesmo estatuto de práticas cuja natureza semiótica está no sentido que adquirem a cada vez que se repetem: no prazer do fazer de novo, num puro contato estésico, enfim, no sentir o outro numa modalidade de encontro significante por si só - outro que pode ser o parceiro com o qual danço, o cavalo no qual monto, o café, o jornal, o cigarro, a própria programação da TV à qual me exponho. Pensado nesses termos, o hábito ganha estatuto semiótico e deixa de ser objeto apenas dos estudos culturais sobre televisão que problematizam a inserção da TV no nosso cotidiano. Pensar no hábito de ver $T V$ é, do ponto de vista semiótico, perguntar como esse próprio contato com a televisão significa, mesmo quando se liga a TV para passar o tempo, para esvaziar a cabeça, para não pensar em nada, para apenas nos fazer companhia. É pensar em um sentido que se instaura quando experimentamos a $\mathrm{TV}$, sentimos a $\mathrm{TV}$, sem sequer tentar compreendê-la ou nos determos nos conteúdos por ela veiculados. Para descrever como esse sentido se dá no âmbito específico da TV é preciso antes, porém, tentar compreender o próprio hábito como um tipo possivel de estesia.

\section{Hábito como estesia}

A descrição do hábito, na perspectiva que aqui nos interessa, filia-se à interpretação mais geral que Eric Landowski propõe do livro-testamento de Greimas, Da Imperfeição (1997/2002) ${ }^{1}$. Nesse

1. Uma visão mais geral da interprelação que $\mathrm{E}$. Landowski propôe deste livro pode 
livro, que foge completamente da ortodoxia e da metalinguagem dos seus demais trabalhos, o desafio lançado por Greimas aos seus colaboradores foi o desenvolvimento de uma inteligência do sensivel. Trata-se agora de compreender um sentido cuja particularidade é justamente ser sentido: um sentido sentido, como bem resume Landowski. A priméira consequêência metodológica de tal proposta é o desprendimento da semiótica de um corpus textual de referência (textos stricto sensu) e a sua conseqüente preocupação em descrever agora um sentido que se dá em ato, seja nas experiências individuais, seja nas práticas sociais cotidianas, na qual se inclui o hábito de ver $T V$ e ao qual voltaremos mais adiante. O que se postula, em última instấncia, a partir dos caminhos abertos pelo Da Imperfeição, é compreender e descrever - através de uma semiótica que se apresenta, agora, mais como uma prática reflexiva que como um método - o modo como o contato com o outro-objeto e a presença mesma das coisas faz sentido. Da Imperfeição abre caminho para tratarmos dessas interaçồes como um regime de sentido de outra ordem - da ordem do vivido. Não mais, portanto, um sentido realizado e, como tal, manifesto como um discurso enunciado, mas, agora, esse sentido em ato, que se constrói em situação, no mómento mesmo em que se dá a co-presença ètre sujeito e objeto.

Superando o clássico dualismo, que se configurou inclusive na semiótica, entre o sensitivo e o cognitivo, Da Imperfeição aponta a necessidade de descrever como o sentido inteligível já incorpora o sensivel e como também há, na perspectiva inversa, uma inteligibilidade no sensivel. Frente a esta intersecção, o desafio posto é o de integrar na análise as duas dimensões intrínsecas a qualquer experiência humana - o saber (o conhecer) e o sentir (ou o

ser encontrada em Da imperfeição, o livro do qual se fala (2002), incluído na tradução brasileira. Há, no entanto, uma série de desdobramentos téricoconceituais propostos por Landowski, a partir de Da Imperfeição, em seus trabalhos mais recentes. Cf., por exemplo, "Sobre el contagio", in R. Dorra, E. Landowski, A. C. Oliveira (eds.). Semiótica, estesis, estética, São Paulo/Puebla, EDUC/UAP; "En deçà ou au-delà des stratégies: la presénce contagieuse", $\mathrm{Ca}$ derno de Discussão do Centro de pesquisas Sociossemíticas, N7, São Paulo, 2001, e, para uma visão mais geral em termos de propostas para uma semiótica do sensivel, Passions sans nom, Paris, PUF, 2003 (no prelo). 
sabor, nos termos de Greimas). É na instauração desse percurso teórico que estão as balizas do Da Imperfeição, ancoradas agora :na relação entre semiótica e estética, pois o próprio deste tipo de experiência é justamente convocar uma dessas dimensões mobilizando a outra. Haveria, no entanto, uma experiência estética que não fosse aquela tradicionalmente associada ao deslumbramento e ao sublime convocados pela grande Arte? Greimas postula que sim. Partindo da análise de cinco textos literários, nos quais se constrói um simulacro desse tipo de experiência, ele chama nossa atenção para o deslumbramento (um tipo de êxtase) que também se produz nas experiências cotidianas, sempre que um outro-objeto provoca uma espécie de fratura ressemantizadora do dia-a-dia do eu-sujeito. É justamente na reinterpretação que Landowski propõe dessas fraturas, indicadas por Greimas, que se insere a nossa discussão sobre o estatuto estésico do hábito.

Landowski lembra que, na maioria das interpretações propostas para essa primeira parte do livro de Greimas, denominada " $\mathrm{A}$ fratura", a aparição do estético tem o estatuto de um evento puramente acidental que se configura como o próprio objeto de busca de um sujeito disjunto de um sentido (para a sua vida cotidiana, em última instância). Em conformidade com modelo narrativo canônico, o que se tem aqui, inicialmente, é um sujeito em estado de carência (falta de sentido) provocado pelas reiterações de rotinas do cotidiano que, por seu desgaste, o dessemantizam. Frente à previsibilidade inevitável da rotina (o esperado), resta a esse sujeito esperar o inesperado, o tal momento deslumbrante: uma espécie de ruptura provocada por uma relação sensivel com um objeto que, fortuitamente, absorve-o, domina-o, impõe-lhe sua presença $e$, por meio de uma comoção 'estésica' revela-lhe justamente esse sentido outro (Landowski 2002: 132). Rompe-se assim, por meio dessa fratura, com uma espécie de anestesia do sujeito que, nessa perspectiva interpretativa, seria inerente às reiterações da cotidianidade. Diante de tal quadro, não haveria escapatória: no dia-a-dia, não existiria lugar para um sentido outro, um sentido que não é mais meramente denotativo ou tão somente da ordem do inteligível (teríamos então a condenação do sujeito à falta de um sentido diferente ou, quem sabe, 
de um sentido mesmo para a vida?). Restaria ao sujeito apenas a esperança de, na sua vida aplainada, deparar-se com algo extraordinário que transformasse, por um momento que fosse, a anestesia quase constitutiva do seu dia-a-dia numa estesia ressemantizadora desse cotidiano: um tipo de sentido sentido (sensivel). Por esse caminho interpretativo, a noção de hábito que, em qualquer de suas acepções, define-se justamente pela deliberada recorrência de um mesmo fazer, só poderia estar associada à insignificância dessas repetições, à mesmice do dia-a-dia ou, se preferirmos, à consentida anestesia do cotidiano.

Diferente da maioria dos comentaristas do Da Imperfeição, que adotam essa interpretação catastrofista (ou acidentalista) do livro de Greimas, Landowski (2002) postula, ao contrário, que o hábito faz sentido. Nessa perspectiva, o hábito pode também ser pensado como um sentido outro que não depende mais do fora do comum, do acidente estésico — irrepetível, efêmero, fortuito —, mas que se instaura, ao contrário e justamente, a partir de um contato reiterativo entre sujeito e objeto, no qual se produz uma espécie de aprendizado entre eles. Trata-se agora de um sentido que se constrói, nos termos de Landowski, como um saber-ser em relação a: uma espécie de ajustamento sensível entre sujeito e objeto produzido pela apreensão contínua (progressiva) de um a respeito do outro $^{2}$. Landowski trata, preferencialmente, desse aprendizado mútuo nas interações corpo a corpo, como entre um casal que dança ou entre o cavaleiro e sua montaria, por exemplo. Nesse caso, o hábito se identifica, segundo ele, com um ajustamento somático e progressivo de duas maneiras de ser, de duas existências corporais ou, a rigor, de dois habitus, na acepção primeira do termo (etimológica). O que está por trás dessa noção de hábito é, antes de mais nada, a pressuposição de que, convocado pelas qualidades sensíveis (materiais, inclusive) ou pelo apelo figurativo do objeto, o sujeito pode ir conhecendo-o melhor, apreendendo-o em profundidade, deixandose como que se contagiar por ele, até chegar a amá-lo: ou seja, a

2. Veja mais a respeito em Eric Landowskl, "Saveur l'autre", in Passions sans nom, PUF, 2003 (no prelo). 
tomar gosto por algo que tanto pode ser uma coisa, uma pessoa, uma prática.

O que significa exatamente esse tomar gosto? Sem desconsiderar que há distintas formas de gosto, determinadas por diferentes regimes de interação entre sujeito e objeto, aquela que nos interessa aqui corresponde essencialmente a uma experiência de fruição (Cf. Landowski 1997). A condição essencial para que se configure essa forma de gosto é o reconhecimento, pelo actante sujeito (S), do objeto sintático (O), que anima sua busca, como um autêntico sujeito, dotado, como tal, da capacidade de agir e de agradar-lhe. Não importa se esse objeto sintático é um objeto mesmo (uma coisa) ou um sujeito propriamente dito (um ser humano). $\mathrm{O}$ que importa é que o sentido da relação que aqui se estabelece está na presença sensível de um ao outro, como se tal objeto, agindo como sujeito, procurasse (co)mover aquele outro (S) por sua própria presença. É por isso que um quadro, uma paisagem, a programação da televisão podem parecer tão vivos, quase como se fossem dotados de intencionalidade e estivessem ali para se mostrar, para agradar àquele sujeito-ator, para fazê-lo justamente frui-los. É, então, como um tipo de experiência de fruição que se pretende descrever aqui o hábito, inclusive o de assistir à televisão. Há, no entanto, uma particularidade nessa descrição: para ser tratada como hábito, é preciso que a reiteração seja parte constitutiva dessa própria forma de fruição. Ou seja, o hábito é um modo de fruição no qual a presença familiar do objeto é parte daquilo que nele, e em determinadas condições, faz sentido para um sujeito - um sentido outro.

Esse sentido outro que se produz no próprio contato do sujeito com um objeto não está mais agora associado à novidade deslumbrante que se instaura, a partir de uma ocorrência pontual, como uma espécie de descontinuidade no cotidiano conhecido e previsível - algo como a visão que Palomar tem dos seios da mulher deitada na praia. No tipo de situação que aqui nos interessa, o sentido outro, ao contrário, está justamente na familiaridade produzida por uma experiência de fruição inserida na continuidade do cotidiano - algo como ligar a TV todo dia no mesmo horário, no mesmo canal e nas mesmas condições que, por si sós, provocam o sentir 
daquele sujeito. Se um sujeito (S) frui a presença de um determinado objeto $(\mathrm{O})$ e o sentido que se produz nessa relação é o próprio gosto da fruição, estamos aqui diante de uma experiência estésica por excelência. Parece possível então começarmos a entender o hábito, a partir daqui, como um tipo de estesia que se produz justamente a partir da própria reiteração (repetição), e não mais de uma irrupção (quebra da normalidade) qualquer no cotidiano. Numa e noutra situação, o sentido estésico que se instaura depende do reconhecimento pelo sujeito de uma presença sensível do objeto. $\mathrm{Na}$ primeira delas, identificada à emergência do hábitó, o sentido estésico que se instaura depende da duração desse contato: um co-viver ou, se preferirmos, um convívio. Na segunda situação, a presença mesma do objeto só faz sentido para o sujeito porque surge, de modo efêmero, no seu dia-a-dia. Nesse caso, numa posição oposta ao hábito, a estesia se instaura como uma fratura no cotidiano.

Não há qualquer razão que autorize o analista a privilegiar uma experiência em detrimento da outra. Se na primeira parte do livro, denominada justamente "As fraturas", Greimas se detém na descrição desses momentos de deslumbramento (de quebra) no cotidiano, na segunda parte, "As escapatórias", mesmo sem utilizar a palavra hábito, ele nos interroga sobre a possibilidade de ressemantização dos objetos gastos que nos rodeiam e das relações intersubjetivas esgotadas ou prestes a ser (Cf. Greimas 2002: 8589). O que está por trás, por exemplo, da descrição que nos traz Greimas do jardineiro japonês que a cada manhã dispõe um pouco distintamente as pedras e areia no seu jardim, produzindo com quase nada um inesperado quase imperceptível? Parece-nos que, com isso, ele nos abre o caminho para a descrição desse sentido que se constrói dia após dia como uma espécie de revelação de algo ainda desconhecido no conhecido, de um novo sabor no mesmo. Como se dá tal processo que resulta, então, na construção de um hábito? Basicamente, pela descoberta de um gosto pelo gosto da fruição: fruição na qual se renova o gosto do sujeito pelo objeto; gosto que se produz justamente na e pela reiterada fruição de um pelo outro. Desse modo, o objeto que comove aqui o sujeito não existe antes do próprio hábito, mas apenas por seu intermédio. Ou seja, o hábito consiste 
justamente em um modo de interação no qual o sujeito e o objeto sintáticos (e, naturalmente, semióticos) não existem antes de uma forma de gosto que a sua própria relação configura (conforma). $O$ sentido que aqui se instaura é, portanto, pautado pela autoreferencialidade do sujeito: o sentido reside essencialmente no seu gosto pelo gosto desse contato que é por ele próprio forjado, cotidiana e reiteradamente.

\section{Hábito versus rotina: modalizações}

A repetição, que particulariza esse tipo de fruição definidora do hábito, é também o que leva alguns analistas a associá-lo tão somente à inevitável dessemantização das práticas cotidianas. Por esse caminho, o que se postula é uma repetição disfórica que se constituiria muito mais como uma forma de desgosto que de gosto. Em vez do hábito, forma de gosto ressemantizadora, o que se tem aqui é a pura rotina, fruto da dessemantização e do desgaste produzido justamente pela repetição imposta pelo dia-a-dia. O que faz, então, com que a repetição possa ser ora fórica ora disfórica e, conseqüentemente, conformadora tanto do hábito quanto da rotina? Uma explicação pode estar na sintaxe modal que determina uma e outra situação. Nesta última situação (a rotina), a repetição é o resultado de um dever-querer no qual o sujeito cumpre um programa determinado por destinador social, cultural, jiológico quaisquer. Um exemplo: há quem fome banho e vista-se com roupas limpas todo dia apenas por um dever-querer que the é imposto por um tipo de controle social (o cônjuge, o emprego que exige boa aparência, etc.). Na primeira situação (o hábito), ao contrário, a repetição é voluntária e fruto, antes de mais nada, de um querer-querer de um sujeito liberado de imposições exteriores ou anteriores. Um outro exemplo, explorando a mesma situação: o do individuo que se banha e se veste com roupas limpas todo dia, movido apenas pelo gosto da fruição do próprio banho, do sentir o conforto, o cheiro das roupas limpas, já que não há cônjugue ou amigos, ou nada que o faz fazer isso a não ser o seu querer-querer e, igualmente importante, o saber do seu sabor. Nesse caso, o imperativo da repetição é, sobretudo, o próprio 
prazer do sujeito, o já mencionado gosto da fruição: querer-fazer é, aqui, tão ou mais importante que o fazer mesmo. No outro caso, porém, a repetição se impōe como uma obrigação, de tal maneira que, sobredeterminado pelo dever, o querer-fazer, nesse caso, manifesta-se muito mais como uma espécie de automatismo que faz fazer (o saber do seu dever).

Considerado assim como uma repetição volitiva e ressemantizada a cada vez, o hábito poderia ser tratado como um tipo de programa no qual o sujeito seria, a um só tempo, seu próprio destinador e objeto. Destinador porque é, sobretudo, a sua própria vontade o que deflagra o percurso de busca. Objeto porque, se cabe ainda falar nesses termos, o que ele busca é essencialmente uma experiência pessoal e intransferível, sem outra motivação a não ser o seu próprio gosto de fruir: experimentar a si mesmo em relação a, ou ainda, experimentar-se (a si) nessa relação e, com isso, descobrir um sentido outro a partir do sentir(-se) o mesmo. Nesse programa de autodestinação, já não cabe mais tratar de valores (objetos-valor) em circulação porque, mesmo que ainda se possa falar nesse processo de um objeto de busca desse sujeito, este se identificará, ao final, ao próprio gosto desse sujeito. $O$ que se tem aqui é, em outras palavras, uma busca de contato do sujeito consigo mesmo (um estar consigo) por meio de um contato ulterior com o outro, ou seja, um objeto sintático com qualidades de sujeito. Esse objeto-sujeito pode ser uma coisa (uma música, um quadro, o café, o cigarro, etc.), um lugar (ou uma paisagem, por exemplo), uma pessoa - uma prática cotidiana, enfim.

Na situação especifica que nos interessa, o sujeito é o próprio responsável pela transformação do seu estado ao ligar a televisão para colocar-se em contato com o fluxo televisual, operação na qual se produz um prazer ou uma forma de gosto identificados aqui à própria experiência de fruir a mesma programação nas mesmas condições. Nisso reside a peculiaridade da operação semiótica em questão: em um contato do espectador com um fluxo televisual cujo sentido depende, justamente, deste ser programado. Afinal, seja qual for a emissora de televisão, sua programação baseia-se, por definição, numa sucessão contínua de arranjos sintagmáticos 
que se repetem em função dos horários e dias da semana. Pela programação da TV, o sujeito vivencia uma certa programação da sua cotidianidade e, nela, também encontra algum sabor: o do reconhecimento de si próprio no (e através do) outro-objeto. $O$ gosto da fruição, nesse caso, está, em grande medida, na familiaridade que a recorrência de tais arranjos e situações produzem. Depois de um dia de atividades estafantes, por exemplo, a TV meramente ligada, muitas vezes, faz com que eu me sinta, enfim, confortavelmente em casa. A simples exposição ao fluxo televisão me autoriza, a partir daí, a não mais pensar em nada. Em outras palavras, ver $T V$ para apenas me sentir não vendo mais nada, fruindo apenas. $\mathrm{O}$ sentido aqui está associado, sobretudo, à maneira ritualizada de passar $o$ tempo com a televisão, sentindo-a como uma prazerosa companhia: tomando gosto pela própria presença da TV (ou por estar em presença da TV) no meu dia-a-dia.

\section{Transmissão direta e hábito}

Esse sentido de presença, identificado aqui à relação estésica que se postula entre o espectador e o fluxo televisual, depende da transmissão direta da própria programação. Independente de esta ser composta por programas gravados ou ao vivo, sua organização enquanto grade (como fluxo) se dá no momento mesmo em que, numa sucessão ininterrupta, tais segmentos são levados ao ar em tempo real, ou seja, a programação vai se fazendo na medida mesmo em que se exibe. A duração na qual se atualiza um dia de programação da TV corresponde, assim, à mesma duração do dia do espectador. É por isso que, muito freqüentemente, o ato de assistir à TV está muito mais associado a determinados momentos do seu dia (após o trabalho, depois do jantar, no domingo à tarde, no fim de noite, etc.) do que ao interesse por assistir a um programa específico. A instauração de hábito depende aqui desse mútuo ajustamento entre o cotidiano do sujeito e a programação da TV, o que só é possível porque a própria concepção do fluxo televisual é orientada pela tentativa de estabelecer essa correspondência. É justamente nessa temporalidade comum ao cotidiano e à TV que se estabelece uma 
conexão produtora de sentido. Configura-se, a partir dessa intersecção temporal, dois regimes de sentido que, apesar das suas descrições distintas dependem, ao final, da inserção do sujeito numa mesma duração (a da transmissão da programação). Vamos à descrição de cada um deles para então relacioná-los.

Operändo em tempo real, a televisão propicia, por um lado, una experiência comum de ver $T V$. Vejo o que os outros estão vendo no momento mesmó em què eles estão vendo. $O$ efeito de contato produzido pela transmissão direta parece ser justamente o resultado do reconhecimento tácito de que algo está se atualizando (se fazendo) agora tanto aqui (espaço do eu) quanto lá (espaço do outro): um contato produzido pela e ná duração. Compartilho com os responsáveis pela emissão (produtores) e com milhares de outros espectadores (receptores) de um mesmo tempo - o tempo instituído pela própria transmissão - e, através deste, todos nos encontramos em um mesmo lugar — um espaço que não se constitui mais materialmente, um espaço simbólico, um espaço vivido tão somente através da transmissão. É nesse tempo e nesse lugar, criados por esse nosso próprio contato com a televisão, que se estabelecem os encontros entre sujeitos enunciantes, É sincronizando o passar o tempo do meu cotidiano com o de grupos sociais mais amplos que a TV instaura um sentido de estar com que se manifesta unicamente na copresença que essa similaridade da programação (todos vendo a mesma coisa, mesmo que não importe exatamente o quê) e essa simultaneidade da sua transmissão (ao mesmo tempo) propiciam. É tão somente o ato de se expor ao fluxo televisual que, ao inserir destinador e destinatário numa mesma dimensão espácio-temporal (a da emissão), instaura um tipo de contato entre os sujeitos. Compõe uma espécie de comunidade imaginária no decorrer da emissão (na duração) e transforma-se, aquém e além dos conteúdos veiculados, numa modalidade de encontro significante em si mesmo.

$O$ sentido de presença que se instaura, nesse caso, identifica-se com um efeito de contato entre sujeitos da enunciação forjados pela própria transmissão. A produção desse tipo de sentido depende do modo como o discurso televisual relaciona a duração da sua transmissão - direta, necessariamente - com uma duração do 
mundo que ele próprio reconstrói narrativamente. $\mathrm{O}$ sentido de presença produzido pelo uso do direto emerge, nesse caso, justamente de um efeito de correspondência entre estas durações: inserindo destinadores e destinatários numa temporalidade que é tanto do discurso (da TV) quanto do mundo (dos fatos), a transmissão faz da sua própria duração a instância de interação, na qual se instaura esse tipo de contato, de acesso direto, entre os sujeitos (ou entre estes e a realidade). Trata-se, aqui, de um sentido de presença que depende de uma relação do espectador com o que vê na tela (regime do olhar) e, cognitivamente, apreende (Cf. Fechine 2001). Por outro lado, pode-se pensar, a partir da mesma operação em tempo real, num sentido que não se produz mais no nivel da enunciação porque depende, antes, de um contato do sujeito consigo mesmo na medida em que o que busca é o seu próprio gosto. Não se trata mais aqui, como na situação anterior, de um sentido que surge de uma relação intersubjetiva (o mencionado efeito de contato entre sujeitos). Trata-se, ao contrário, de uma experiência individual (interior) do sujeito, na medida em que tão somente se deixa captar, estesicamente, pela tela (regime da olhadela) ${ }^{3}$.

Nesse caso, o sentido que se impõe é o meu próprio sentir o o gosto da fruição — um sentido intra-subjetivo, ou estésico, já que depende de uma relação fusional entre o sujeito e um objeto, que já não pode mais ser recortado autonomamente numa função semiótica. Por que? Porque, agora, já é possível postular, de modo mais assumido, que o objeto com o qual esse sujeito entra em relação já não é mais propriamente a programação da $\mathrm{TV}$, mas sim a sua própria fruição. Ou seja, o que o sujeito busca é, de modo auto-referencial, a sua própria exposição ao fluxo televisual como hábito. É possivel que esse sentido intra-subjetivo seja, em determinadas condições, sobredeterminado justamente pela busca da intersubjetividade latente na transmissão direta da programação (já não haveria nessa

3. Configura-se, agora, um sentido de presença de outra ordem: um sentido mais sensivel que inteligivel, embora seja preciso, logicamente, considerar que o sujeito pode, no processo de recepçāo, passar de um regime a outro. Basta que sua relaçāo com a TV esteja sendo determinada, alternadamente, pelo olhar ou pela olhadela. 
interação entre sujeitos, instaurada pela transmissão direta da programação, um gosto associado ao da própria fruição?). Não parece haver, no entanto, qualquer condicionamento direto de um regime sobre o outro, assim como não há nenhuma relação de excludência entre eles. $O$ que há, num e noutro, é uma mútua implicação entre o tempo cotidiano e o tempo da programação da televisão.

É importante destacar, por fím, como a própria instauração de um sentido de hábito ou de fratura depende desse fa$z e r-s e$ da programação da televisão em tempo real. Acabamos de discutir como esta característica técnico-operacional da TV confere ao próprio ato de ver TV um sentido (o do hábito). $\dot{\mathrm{E}}$ preciso, agora, atentar para como o próprio hábito pode estar na base de um sentido distinto que se produz, ao contrário, como um tipo de fratura no cotidiano, a partir da interrupção da programação normal da televisão. Já vimos que, quando o espectador liga a TV, identificando no fluxo os programas esperados em função de uma determinada grade (dia da semana e horário), o sentido que aqui se estabelece depende justamente desse reconhecimento - dessa familiaridade com a programação, na qual se evidencia o que há de habitual entre a TV e o seu dia-adia. O que acontece, porém, quando as emissoras de TV, as brasileiras inclusive, subvertem toda a sua programação para transmitir, por exemplo, coberturas como a dos atentados terroristas ao World Trade Center (WTC), em Nova Iorque, no histórico dia 11 de setembro de 2001 ? Há uma espécie de quebra da normalidade na programação da TV que, independente dos conteúdos postos em circulação, significa: produz uma espécie de ruptura num cotidiano que faz sentido por si só. A produção de sentido da programação da TV, considerada aqui enquanto fluxo contínuo, indistinto e ininterrupto, parece se definir justo na latência desses momentos: num primeiro momento, por esse mútuo ajustamento - entre o meu dia-a-dia e a programação ordinária da TV - e, num segundo momento, por esse inevitável estranhamento - o acontecimento inesperado e a programação extraordinária da TV. 


\section{Bibliografia}

GREIMAS, Algirdas Julien. (1987). De l'Imperfection. Périgueux: Fanlac.

Da Imperfeição(2002). Tradução de Ana Claudia de Oliveira. São Paulo: Hacker Editores.

ELLIS, John (1982). Visible fictions. Cinema, television, video. London: Routledge \& Kegan Paul.

FECHINE, Yvana (2001). Televisão e presença: uma abordagem semiótica da transmissão direta em gêneros informativos. Tese de doutorado, Programa de Estudos Pós-graduados em Comunicação e Semiótica - PUCSP.

FISKE, John (1992). Television culture. London: Routledge.

LANDOWSKI, Eric (1997). Gosto se discute, in LANDOWSKI, Eric e FIORIN, José Luís (eds.). O gosto da gente, o gosto das coisas. São Paulo: EDUC, 1997.

(1998). Pour l'habitude, Caderno de Discussão do Centro de Pesquisas Sociossemióticas, $N^{\circ} 4$. São Paulo: Edições do CPS.

(2002). De 1'Imperfection, o livro do qual se fala, in GREIMAS, Algirdas Julien. Da Imperfeição (2002). Tradução de Ana Claudia de Oliveira. São Paulo: Hacker Editores.

WILLIAMS, Raymond (1975). Television: technology and cultural form. Nova York: Schoken Books. 